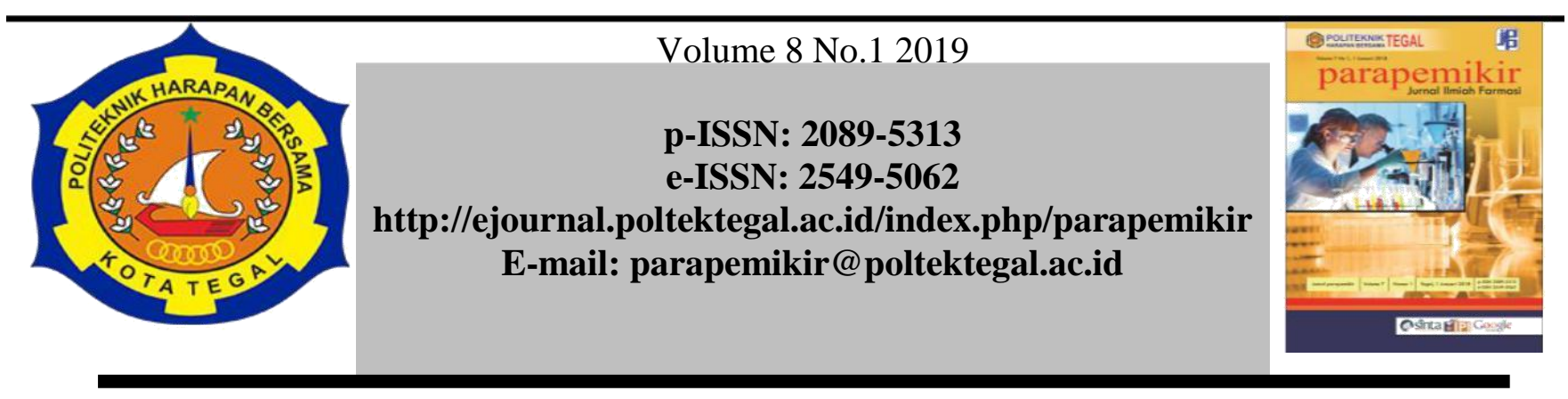

\title{
PENENTUAN NILAI SPF ( SUN PROTECTION FACTOR) EKSTRAK DAN FRAKSI DAUN KECOMBRANG (ETLINGERA ELATIOR) SECARA IN VITRO MENGGUNAKAN METODE SPEKTROFOTOMETRI
}

\author{
Oktariani Pramiastuti ${ }^{1}$ \\ ${ }^{1}$ Prodi S1 Farmasi STIKes Bhakti Mandala Husada Slawi \\ Email : oktariani.pram@gmail.com
}

\section{Article Info \\ Article history: \\ Received Desmber \\ 2018 \\ Received in \\ revised form \\ Desember 2018 \\ Accepted Januari \\ 2019 \\ Available online \\ January 2019 \\ Kata kunci: daun kecombrang, $S P F$, ekstrak air, fraksi $n$ - heksan, fraksi etil asetat.}

Keywords:

Kecombrang Leaf, $S P F$, Water Extract, $n$-hexane fraction, ethyl acetate fraction.

\begin{abstract}
Abstrak
Sinar matahari sangat dibutuhkan oleh semua makhluk hidup untuk kelangsungan hidupnya. Di satu pihak, sinar matahari diperlukan oleh manusia sebagai sumber energi dan penyehat kulit dan tulang. Daun Kecombrang mengandung senyawa fenolik, yang mampu memberikan perlindungan terhadap sinar UV dan berpotensi tabir surya. Penelitian ini bertujuan untuk memperkirakan nilai SPF dari ekstrak air, fraksi nheksan dan fraksi etil asetat daun kecombrang. Penelitian dilakukan secara in vitro menggunakan metode Spektrofotometri UV-Vis. Absorbansi ekstrak dan fraksi daun Kecombrang diukur pada panjang gelombang sinar UV-B yaitu 290-320 nm. Penentuan nilai SPF didasarkan pada persamaan Mansur. Uji fitokimia secara KLT ekstrak air, fraksi n-hkesan dan fraksi etil asetat masing-masing positif terhadap fenol.Hasil pengujian menunjukkan bahwa ekstrak air daun Kecombrang memiliki

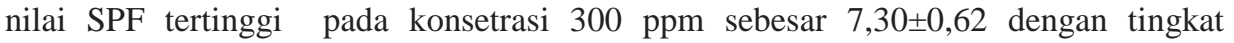
kemampuan tabir surya ekstra. Fraksi $\mathrm{n}$ heksan daun kecombrang memiliki aktivitas perlindungan yang tertinggi dengan nilai SPF 17,57 $\pm 2,49$ dengan tingkat kemampuan tabir surya Ultra pada konsentrasi 300 ppm. Sedangkan fraksi etil asetat memiliki nilai SPF paling tinggi yaitu 2,65 $\pm 0,12$ dengan kategori perlindungan minimal. Hasil analisis data menunjukkan adanya perbedaan signifikan antara ekstrak air daun Kecombrang dengan fraksi n-heksan dan fraksi etil asetat. Pada penelitian ini dapat disimpulkan bahwa fraksi n-heksan daun kecombrang memiliki nilai SPF paling tinggi sehingga berpotensi sebagai tabir surya terhadap proteksi sinar UV-B
\end{abstract}

\section{abstract}

$\overline{\text { Sunlight is needed by all living things to their survival. One of the benefits of sunlight }}$ is as sources of energy and making healthy skin and bones. Kecombrang leaf contains phenolic compound which is able to give protection for UV light and have potentially sunscreens. The research aimed to determine of SPF of water extract, n-hexane fraction, and ethyl acetate fraction of kecombrang leaf. The research was in vitro by using spectrophotometry UV-Vis method. The absorbance of extract and fraction of kecombrang leaf was measured at a UV-B light wave length of 290-320 nm. Determination of SPF was based on Mansur equation. Phytochemical test in TLC of water extract, n-hexane fraction, and ethyl acetate fraction was positive for phenol in each. The result showed that water extract of kecombrang leaf had the highest SPF at concentration of $300 \mathrm{ppm}$ numbered $7.30 \pm 0.62$ with level of extra sunscreens ability; nhexane fraction of kecombrang leaf had the highest protection activity in a SPF of $17.57 \pm 2.49$ with level of ultra-sunscreens ability in a concentration of $300 \mathrm{ppm}$; while ethyl acetate fraction had the highest SPF namely $2.65 \pm 0.12$ with the minimum protection. The data analysis stated that there was a significant difference between water extract of kecombrang leaf and fractions of $n$-hexane and ethyl acetate. To sum 
Oktariani Pramiastuti, Vol 8 (1) 2019 pp 14-18

up, n-hexane fraction of kecombrang leaf had the highest SPF so that it had potentially as sunscreens for UV-B light protection

C2019PoliteknikHarapanBersamaTegal

Alamat korespondensi:

Prodi DIII Farmasi Politeknik Harapan Bersama Tegal

Gedung A Lt.3. Kampus 1

J1. Mataram No. 09 Kota Tegal, Kodepos 52122

Telp. (0283) 352000

p-ISSN: 2089-5313

E-mail: parapemikir_poltek@yahoo.com

e-ISSN: 2549-5062 


\section{Pendahuluan}

Sinar matahari sangat dibutuhkan oleh semua makhluk hidup untuk kelangsungan hidupnya. Disatu pihak, sinar matahari diperlukan oleh manusia sebagai sumber energi dan penyehat kulit dan tulang ${ }^{1}$. Sinar matahari yang sampai dipermukaan mempunyai dampak negatif terhadap kulit yaitu sinar UV A dan UV B ${ }^{2}$. Kedua sinar ultraviolet ini bekerja secara sinergis sehingga dibutuhkan suatu pencegahan atau perlindungan untuk mengurangi dampak buruk pada kulit akibat radiasi sinar UV A dan UV B.

Efek merugikan yang ditimbulkan oleh radiasi sinar ultraviolet adalah terjadinya kerusakan epidermis yang biasa disebut sengatan surya, pengkerutan kulit, penuaan dini, pigmentasi serta pada penyinaran yang lama dibawah terik sinar matahari mengakibatkan perubahan pada jaringan pengikat dalam lapisan stratum korneum.

Pencegahan dampak buruk karena paparan sinar matahari dapat dilakukan dengan menggunakan tabir surya. Tabir surya adalah sediaan yang digunakan untuk melindungi kesehatan kulit manusia dari pengaruh negatif akibat radiasi sinar matahari.

Ekstrak Etanol daun Kecombrang memiliki aktivitas antioksidan dan flavanoid ${ }^{3}$. Flavanoid, tanin, antraquinon, sinama dan lain-lain telah dilaporkan memiliki kemampuan sebagai perlindungan terhadap sinar UV ${ }^{1}$. Senyawa fenolik khususnya golongan flavanoid dan tanin mempunyai potensi tabir surya karena adanya gugus kromofor (ikatan rangkap tunggal terkonjugasi) yang mampu menyerap sinar UV baik UV A maupun UV B, sehingga mampu megurangi intensitasnya pada kulit ${ }^{1,2,3}$.

Nilai SPF berkisar antara 0 sampai 100, dan kemmapuan tabir surya yang dianggap baik berada diatas 15. Menurut FDA (Food Drug Administration) pembagian kemampuan tabir surya adalah minimal (SPF antara 2-4), sedang (SPF antara 4-6), Ekstra (SPF antara 6-8), maksimal (SPF antara 8-15) dan ultra (SPF alebih dari 15) ${ }^{5}$.

Penentuan efektivitas tabir surya dilakukan dengan menentukan nilai SPF secara in vitro dengan menggunakan spektrofotomteri UV-vis. Penelitian ini bertujuan untuk mengetahui nilai SPF ekstrak air, fraksi n-heksan dan fraksi etil asetat Daun Kecombrang dengan menggunakan persamaan Mansur.

\section{Metodologi Penelitian}

Penelitian ini merupakan eksperimental murni yaitu menentukan efeketivitas tabir surya berupa nilai SPF dari ekstrak dan fraksi daun Kecombrang menggunakan spektrofotometri UV-Vis.
Alat : Spektrofotometri UV-Vis (Shimadzu), rotary evaporator, waterbath, corong pisah (pyrex), timbangan analitik, pelat silika GF 254 dan alat-alat gelas (pyrex).

Bahan : Air, n-heksan, etil asetat dan daun kecombrang yang diperoleh di jalan Cut Nyak Dhien Kalisapu, Slawi, Kabupaten Tegal. Daun kecombrang selanjutnya didterminasi di laboratorium Biologi Prodi S1 Farmasi STIKes Bhakti Mandala Husada Slawi. Selanjutnya sampel dibuat simplisia.

Ekstraksi serbuk daun Kecombrang dilakukan dengan metode maserasi menggunakan pelarut air. Sebanyak 200 gram serbuk daun Kecombrang ditambah $2000 \mathrm{~mL}$ bagian air dengan perbandingan 1:10, dan dimaserasi selama 2 hari. Sebanyak 100 gram serbuk daun Kecombrang dimaserasi selama $2 \times 24$ jam menggunakan $600 \mathrm{~mL}$ pelarut $\mathrm{n}$-Heksan, selanjutnya dilakukan remaserasi dengan pelarut etil astat sebanyak $600 \mathrm{~mL}$ selama 2x 24 jam. Selanjutnya masing -masing filtrat dikentalkan menggunakan rotary evaporator.

Skrining fitokimia dilakukan pada ekstrak dan fraksi daun Kecombrang meliputi pemeriksaan flavanoid, saponin, tanin-polifenol, steroid, triterpenoid, alkaloid dan kuinon.

Penentuan Nilai SPF Ekstrak dan Fraksi Daun Kecombrang Masing-masing sampel ekstrak air, fraksi n-heksan dan fraksi etil asetat daun Kecombrang dilarutkan dalam air dan dibuat dalam konsentrasi 100 ppm, 200 ppm dan 300 ppm. Spektrofotometer UV-vis dikalibrasi terlebih dahulu dengan menggunakan air sebanyak $1 \mathrm{~mL}$. Pengukuran nilai SPF, sampel diukur serapannya dengan spektrofotometer UV -vis tiap $5 \mathrm{~nm}$ pada rentang panjang gelombang dari $290 \mathrm{~nm}$ sampai panjang gelombang $320 \mathrm{~nm}$ dan dilakukan tiga kali penentuan tiap poinnya, diikuti dengan aplikasi persamaan Mansur 6,7

Analisa Data Nilai SPF dianalisis menggunakan metode Mansur

$$
S P F_{\text {spectrophootometric }}=C F \times \sum_{290}^{320} E E(\lambda) \times I(\lambda) \times A b s(\lambda)
$$

Keterangan :

EE : Spektrum Efek Eritema

I : Spektrum Intensitas Cahaya

Abs: Absorbansi sampel tabir surya

$\mathrm{CF}$ : Faktor Koreksi $(=10)$

Nilai EE x I adalah konstan dan ditunjukkan pada Tabel 1 berikut :

Tabel 1. Normalized product function digunakan pada kalkulasi SPF

\begin{tabular}{lll}
\hline No. & $\begin{array}{l}\text { Panjang } \\
\text { Gelombang }(\lambda \mathrm{nm})\end{array}$ & EE X 1 \\
\hline 1. & 290 & 0.0150 \\
2. & 295 & 0.0817 \\
3. & 300 & 0.2874 \\
4. & 305 & 0.3278 \\
5. & 310 & 0.1864 \\
6. & 315 & 0.0839 \\
7. & 320 & 0.0180 \\
\hline Total & \multicolumn{2}{c}{} \\
\hline
\end{tabular}


Cara Perhitungan

1. Nilai serapan yang diperoleh dikalikan dengan nilai EE $x \quad 1$ untuk masing-masing panjang gelombang yang terdapat pada tabel 1 .

2. Hasil perkalian serapan dan EE x1 dijumlahkan.

3. Hasil Penjumlhan kemudian dikalikan dengan faktor koreksi yang nilainya 10 untuk mendapatkan nilai SPF ${ }^{8}$.

Data yang diperoleh (nilai) SPF dari masingmasing ekstrak air, fraksi n-heksan dan etil asetat dianalisis menggunakan program SPSS. Uji homogenitas dilakukan dengan uji Levene,s Test.Uji normalitas data dilakukan dengan uji KomolgrovSmirnov.Data kemudian dianalisis dengan One Way ANOVA untuk membandingkan nilai SPF.

\section{HASIL DAN PEMBAHASAN}

Berdasarkan hasil identifikasi tanaman yang dilakukan di Laboratorium Biologi Farmasi Prodi S1 Farmasi STIKes Bhakti Mandala Huasada Slawi menyatakan bahwa tanaman yang digunakan pada penelitian ini adalah tanaman Kecombrang dengan spesies Etlingera elatior.

Hasil Fraksinasi

Hasil maserasi dan fraksinasi menunjukkan adanya perbedaan nilai randemen ekstrak daun Kecombrang yang dimaserasi dan fraksinasi menggunakan pelarut yang berbeda. Ekstrak air memiliki randemen paling tinggi dibandingkan fraksi n-heksan dan etil asetat (tabel 2).

Tabel 2. Randemen ekstrak air dan fraksi n-heksan dan etil asetat daun Kecombrang.

\begin{tabular}{lll}
\hline No & Ekstrak/Fraksi & Randemen \\
\hline 1 & Ekstrak Air & $21,3 \%$ \\
2 & Fraksi n-heksan & $2,16 \%$ \\
3 & Fraksi etil asetat & $2,14 \%$ \\
\hline
\end{tabular}

Skrining Fitokimia.

Hasil skrining fitokimia Skrining fitokimia dilakukan untuk memberikan gambaran tentang golongan senyawa yang terkandung dalam ekstrak, dalam hal ini adalah ekstrak air daun kecombrang (Etlingera elatior). Hasil skrining fitokimia air daun kecombrang (Etlingera elatior) yang diperoleh dalam penelitian ini menunjukkan bahwa senyawa flavonoid, saponin, tanin-polifenol, triterpenoid, alkaloid, serta kuinon dapat tertarik dalam pelarut air. Hal ini disebabkan air merupakan pelarut universal yang bersifat polar. Oleh karena itu, air akan melarutkan senyawa-senyawa yang bersifat polar, dan sebaliknya, tidak melarutkan senyawa nonpolar.

Sedangkan hasil skrining fitokimia fraksi n-heksan daun Kecombrang menunjukkan adanya senyawa flavanoid, steroid, tanin dan polifenol. Fraksi etil asetat daun Kecombrang memberikan hasil skrining fitokimia adanya metabolit sekunder flavanoid, tanin dan polifenol (tabel 3).
Tabel 3. Hasil skrining Fitokimia Ekstrak dan Fraksi Daun Kecombrang

\begin{tabular}{llccc}
\hline No Uji & $\begin{array}{c}\text { Ekstrak } \\
\text { Air }\end{array}$ & $\begin{array}{c}\text { Fraksi n- } \\
\text { heksan }\end{array}$ & $\begin{array}{c}\text { Fraksi } \\
\text { etil } \\
\text { asetat }\end{array}$ \\
\hline 1 & Flavanoid & + & + & + \\
2 & Tanin-Polifenol & + & + & + \\
3 & Steroid & - & + & - \\
4 & Alkaloid & + & - & - \\
5 & Triterpenoid & + & - & - \\
6 & Kuinon & + & - & - \\
7 & Saponin & + & - & - \\
\hline
\end{tabular}

Penentuan Nilai SPF Ekstrak dan Fraksi Daun Kecombrang Penentuan nilai SPF ekstrak air dan fraksi n-heksan serta etil asetat daun Kecombrang dilakukan secra in vitro menggunakan alat spektrofotometer UV-vis dengan panjang gelombang $290 \mathrm{~nm}-320 \mathrm{~nm}$. Panjang gelombang ini mewakili panjang gelombang sinar UV B (290230nm) yang berada pada daerah eritmogenik yang dapat menumbulkan sengatan sinar matahari. Sinar UV-B merupakan kelompok sinar berbahaya yang dapat menyebabkan kerusakan lebih cepar dan lebuh mudah dibanding sunar UV A ${ }^{1,9}$. Air digunakan sebagai pelarut dan blangko karena air relatif tidak memberikan gangguan serapan terhadap senyawa yang dilarutkan.

Hasil pengukuran absorbansi ekstrak air daun Kecombrang menunjukkan absorbansi tertinggi pada panjang gelombang $290 \mathrm{~nm}$, dimana nilai absorbansi semakin menurun dan paling rendah pada panjang gelombang $320 \mathrm{~nm}$. Demikian juga absorbansi pada fraksi n-heksan dan etil asetat daun kecombrang tertinggi pada panjang gelombang 290 $\mathrm{nm}$ dan terendah pada anjang gelombang $320 \mathrm{~nm}$.

Nilai SPF diperoleh dari hasil pengukuran absorbansi pada panjang gelombang $290-320 \mathrm{~nm}$ berdasarkan persamaan Mansur. Hasil pengukuran pada penelitian ini diperoleh nilai SPF paling tinggi berurutan pada fraksi n-heksan, ekstrak air dan fraksi etil asetat. Semakin tinggi konsentrasi ekstrak semakin tinggi nilai SPF nya (tabel 4).

Tabel 4 Nilai SPF ekstrak air, fraksi n-heksan, fraksi etil asetat Daun Kecombrang

\begin{tabular}{|c|c|c|c|c|}
\hline \multirow[t]{2}{*}{ Uraian } & \multicolumn{3}{|c|}{ SPF } & \multirow[t]{2}{*}{ Kategori } \\
\hline & 100 & $200 \mathrm{pp}$ & m 300 ppm & \\
\hline \multirow[t]{2}{*}{ Ekstrak air } & 2,503 & $\pm 4,128$ & $\pm 7,305$ & \multirow[t]{2}{*}{ \pm ekstra } \\
\hline & 1,462 & 0,314 & 0,626 & \\
\hline Fraksi & $1-5,665$ & $\pm 11,700$ & $\pm 17,579$ & \multirow{4}{*}{$\begin{array}{l} \pm \text { ekstra- } \\
\text { ultra } \\
\pm \text { minimmal }\end{array}$} \\
\hline heksan & 0,208 & 1,678 & 2,495 & \\
\hline Fraksi & il11,436 & $\pm 2,655$ & $\pm 1,736$ & \\
\hline asetat & 0,045 & 0,121 & 0,029 & \\
\hline
\end{tabular}

Dari ketiga ekstrak dan fraksi tersebut masing -masing memiliki aktivitas sebagai tabir surya dengan ditandai dengan nilai SPF yang diperoleh. Aktivitas tabir surya ini dikarenakan kandungan metabolit sekunder yang terkandung dalam daun Kecombrang yaitu golongan flavanoid dan taninpolifenol, dimana metabolit golongan ini memiliki kandungan fenol. 
Fraksi etil asetat memberikan nilai SPF paling rendah dengan kategori minimal, hal ini disebabkan proses penarikan atau ekstraksi dilakukan dengan metode remaserasi yang diawali dengan maserasi menggunakan pelarut n-heksan yang bersifat non polar. Sehingga dimungkinkan senyawa atau metabolit sekunder yang memberikan aktivitas tabir surya sudah tertarik terlebih dahulu oleh n-heksan. Sedangkan etil asetat bersifat semipolar.

Hal ini sesuai dengan hasil skrining fitokimia pada ekstrak air, fraksi n-heksan dan fraksi etil asetat yang menunjukkan adanya kandungan fenol. Fenol merupakan senyawa aromatik yang dapat memberikan senyawa aromatik yang dapat memberikan serapan didaerah spektrum UV karena adanya ikatan rangkap tunggal terkonjugasi sehingga dapat berkhasiat sebagai tabir surya ${ }^{10}$.

Radiasi sinar UV yang diserap selama terkena paparan sinar UV menyebabkan molekulnya tereksitasi menjadi bentuk yang memiliki energi lebih besar. Dan ketika molekul ini kembali ke keadaan awal, energi diemisikan dalam bentuk yang lebih rendah daripada energi yang diserap sehingga dapat memberikan aktivitas tabir surya ${ }^{11}$.

Data nilai SPF selanjutnya dianalisis menggunakan SPSS dengan One Way ANOVA, dimana data bersifat homogen dan normal. Diketahui antara ekstrak air, fraksi n-heksan dan fraksi etil asetat terdapat perbedaan yang signifikan dengan nilai $\mathrm{p}$ $<0,005$. Oleh karena itu dpat disimpulkan bahwa proses ekstraksi dengan maserasi dan fraksinasi mempengaruhi aktivitas tabir surya dari daun Kecombrang dimana fraksi n-heksan merupaka fraksi yang memiliki aktivitas tabir surya dengan nilai SPF paling tinggi.

\section{KESIMPULAN}

Ekstrak air, fraksi n-heksan dan fraksi etil astetat daun Kecombrang memiliki aktivitas tabir surya. Berdasarkan persamaan Mansur, nilai SPF paling tinggi terdapat pada fraksi n-heksan sebesar 17,579 \pm 2,495 diikuti ekstrak air sebesar 7,305 \pm 0,626 dan fraksi etil asetat sebesar 1,736 $\pm 0,029$ pada konsentrasi 300 ppm.

\section{REFERENSI}

[1] Ismail, I., Handayany. W.G., Wahyuni, D., Juliandri. 2014. Formulasi dan Penentuan Nilai SPF (Sun Proetecting Factor) Sediaan Krim Tabir Surya Ekstrak Etanol Daun Kemangi ( Ocimum sanctum L). JF FIK UINAM

[2] Shovyana, H.H., A. Karim Zulkarnain. 2013. Physical Stability and Activity of Cream W/O Etanolic Fruit Extract of Mahkota Dewa (Phaleria macrocarpha (Scheff.) Boerl) as A a Sunscreen. Traditional Medicine Journal 18(2), Fakultas Farmasi UGM. Yogyakarta.

[3] Prastiyo.A.B., Pramiastuti.O dan Zen. D.A. 2018. Penentuan Kadar Total Fenolik dan Uji Aktivitas Antioksidan Ekstrak Etanol Daun Kecombrang Menggunakan Metode DPPH. Skripsi. STIKes Bhamada Slawi.

[4] Sa'adah, L. 2010. Isolasi dsan Identifikasi Senyawa Tanin dari Daun Belimbing Wuluh (Averrhoa bilimbi L). Jurusan Kimia UIN Maulana Malik Ibrahim Malang

[5] Damogalad, V., Hosea Jaya Edy dan Hamidah Sri Supriadi. 2013. Formulasi Krim Tabir Surya Ekstrak Kulit Nanas (Ananas comosus L Merr) dan Uji In Vitro Nilai Sun Protecting Factor ( SPF). Pharmacon Jurnal Ilmiah Farmasi UNSRAT Vol 2. No.2. Manado. Program Studi Farmasi FMIPA UNSRAT.

[6] Pratama, A.W., dan Zulkarnain K. 2015. Uji SPF in Vitro dan Sifat Fisik Beberapa Produk Tabir Surya yang Beredar di Pasaran. Majalah Farmaseutik, Vol 11 No.1. Fakultas Farmasi UGM Yogyakarta.

[7] Mansur JS, et al. 1986. Determination of Sun Protection Factor for Spectrophotometry. An Bras Deramtol.

[8] Yulianti. E., Adelsa. A dan Putri. A. 2015. Penentuan Nilai SPF (Sun Protecting Factor) Ekstrak Etanol $70 \%$ Temu Mangga (Curcuma mangga) dan Krim ekstrak etanol $70 \%$ Temu Mangga (Curcuma mangga) Secara In Vitro Menggunakan Metode Spektrofotometri. Majalah Kesehatan. Vol 2, No.1. FKUB.

[9] Suyatno, Hidajati, Syarief N., Sri Hidayati, Rinaningsih \& Wakhida Hidayatin Nur. 2007. Uji In Vitro Aktivitas Tabir Surya Senyawa Turunan Sinamat Hasil Isolasi dari Rimpang Kencur (Kaempferia galangal L.).

[10] Harborne, J.B. 1987. Metode Fitokimia: Penuntun Cara Modern Menganalisis Tumbuhan. Bandung: Penerbit ITB.

[11] Wihelmina C.E. 2011. Pembuatan dan Penentuan Nilai SPF Nanoemulasi Tabir Surya Menggunakan Minyak Kencur (Keampferia galanga L.) Sebagai fase MinyakSkripsi. 